\title{
Time of injury in light of prior-to-injury and usual alcohol consumption: an emergency department study
}

This article was published in the following Dove Press journal:

Open Access Emergency Medicine

16 August 2010

Number of times this article has been viewed

\author{
Hervé Kuendig' \\ Lucie Laflamme ${ }^{2}$ \\ Gerhard Gmel' \\ Jean-Bernard Daeppen ${ }^{3}$ \\ Marie Hasselberg ${ }^{2}$
}

'Addiction Info Switzerland, Research Institute, Lausanne, Switzerland;

${ }^{2}$ Department of Public Health

Sciences, Karolinska Institutet,

Stockholm, Sweden; ${ }^{3}$ Alcohol

Treatment Center, Lausanne

University Hospital, Lausanne,

Switzerland
Correspondence: Hervé Kuendig Addiction Info Switzerland, Av Ruchonnet I4, CH-I003 Lausanne, Switzerland

Tel $+4|2| 32 \mid 2948$

Fax + 4I 213212940

Email hkuendig@addiction-info.ch
Purpose: To investigate how prior-to-injury and usual alcohol consumption relate to time of injury.

Patients and methods: The associations between injury time of day and day of week and prior-to-injury (labeled as "acute") alcohol intake and hazardous usual alcohol consumption (considered from the point of view of both heavy episodic drinking [HED] and risky volumes of consumption) are assessed using interview data from a randomized sample of 486 injured patients treated in a Swiss emergency department (ED; Lausanne University Hospital).

Results: Acute consumption was associated with both injury time of day and day of week, HED with day of week only, and risky volume with none.

Conclusions: Acute consumption and HED, but not risky volume of consumption, show specific time distributions for injuries. These findings highlight the potential importance of considering the time dimension of an injury when providing emergency care and have additional implications for interventions aimed at influencing the alcohol consumption of injured patients presenting to the ED.

Keywords: acute alcohol consumption, volume of consumption, heavy episodic drinking, trauma patients

\section{Introduction}

As prior-to-injury alcohol consumption, here referred as acute alcohol consumption, is a documented risk factor for injury, ${ }^{1}$ interventions have been designed to identify trauma patients in emergency departments (EDs) and try to influence their drinking patterns. But as knowledge concerning the usual drinking patterns of trauma patients is limited, ${ }^{1}$ successful results of those interventions may be impeded. ${ }^{2}$

Just as population-based alcohol consumption peaks during weekends and evenings, ${ }^{3,4}$ individual consumption often follows a similar pattern. Also, population-based data reveal peaks in injury mortality and morbidity when consumption is high, at weekends and evening/night time; ${ }^{3,5,6}$ an association implicitly known by EDs' staffs and confirmed by individual-based studies. ${ }^{7-12}$ Yet, little is known on the association between usual drinking patterns and the time distribution of injuries. It remains accordingly unclear whether injured patients who are acute drinkers or "usual" hazardous drinkers have similar injury time distribution, something which can have implications for the design and implementation of interventions.

The present study investigates the relationship between alcohol consumption and time of injury, considering both acute (ie, prior to injury) and hazardous (ie, at risk) usual alcohol consumption. Hazardous alcohol consumption is considered from the 
point of view of both risky volumes of usual consumption and of frequent heavy episodic drinking (HED).

\section{Material and methods \\ Study design, setting, and sample}

Data were gathered from interviews compiled within a casecrossover study focusing on the triggering effect on injury of alcohol and cannabis use. ${ }^{13,14}$ Based on a randomized selection of time slots covering day and night time (24/24 hours) and every week day (7/7), 486 injured patients (mean age, 37.9 years; males, 68.3\%) admitted to the ED of the Lausanne University Hospital (Switzerland) were interviewed over 4 one-month periods between September 2005 and July 2006, ie, accounting for seasonal variability. A total of 774 patients were eligible for the study (eligibility criteria: French speaking, age 16 and above, and seeking injury care within 24 hours). Patients with degenerative brain disorders $(n=37)$ or with major trauma $(n=29)$ were excluded on the grounds that they could not manage an interview. Another 160 patients were not contacted due to work overload $(n=115)$, transfers to other wards $(n=43)$, and other reasons $(n=2)$. Of the 548 patients contacted, 60 declined participation $(10.9 \%)$ and 2 were excluded because of poor interview results. The questionnaire followed the protocol developed by the World Health Organization Collaborative Study Group on Alcohol and Injuries. ${ }^{15}$ More information on the sampling frame and inclusion criterion can be found elsewhere. ${ }^{13,14}$ The study was approved by the Ethics Committee for Clinical Research of the Lausanne University Medical School.

\section{Measures}

Time of injury was measured considering both day of week (seven categories/days) and time of day (three categories/ time periods: night/0:00-7:59, day/8:00-15:59, and evening/16:00-23:59). Distribution of injuries across time of day and day of week and their combination is available on request.

Acute alcohol consumption was defined based on the self-reporting of any alcohol consumption in the 6 hours preceding the injury. ${ }^{15}$

The reference period for the measurement of usual alcohol consumption, and thus of hazardous drinking, was the past 12 months. Risky volume was assessed through a quantity-frequency instrument and categorized according to standard recommendations. ${ }^{16}$ Risky volume was set at an average consumption of more than one standard drink, of 10-12 g of pure alcohol, per day for women and of more than two standard drinks for men. HED was defined as the monthly intake of certain amounts of alcohol based on a question about the frequency of consumption of five or more standard drinks of alcohol on the same occasion for men, and four or more for women. ${ }^{4}$

\section{Analyses}

Prevalence of acute and hazardous alcohol consumption was plotted on graphs according to time of day and day of week of the injury. Logistic regression models assessed associations between time of injury and the three alcohol-related measures. Acute consumption (yes $=1$, no $=0$ ), risky volume of consumption (yes $=1$, no $=0$ ), and HED (yes $=1$, no $=0$ ) are regressed on time of day and day of week (both categorical), adjusted for participants' gender and age. Interaction effects between time and day are modeled in a final set of models to assess effect modifications (treated as categorical as for the main effects). Wald tests and odd ratios (ORs), with $95 \%$ confidence intervals (CIs), are given. These analyses were conducted using the software SPSS (version 15.0.1; SPSS Inc, Chicago, IL). ${ }^{17}$

\section{Results \\ Descriptive}

The results showed that $51.8 \%$ of all night-time injuries and $82.6 \%$ of those taking place during the night between Friday and Saturday occurred after acute consumption (Figure 1). Injury prevalence for HED (Figure 2) peaked on Saturday but did not vary much over days and hours for risky volume of consumption (Figure 3). Considering variability of prevalence across time periods of the day (see the legends in Figures 1-3), low variability was observed for risky volume of consumption (between 12.3\% and 15.5\%) and HED (between $30.6 \%$ and $43.3 \%$ ), whereas acute consumption varied more markedly (between $10.2 \%$ during day time and, as mentioned earlier, $51.8 \%$ during night time).

\section{Regression analyses}

As mentioned above and in Table 1, acute alcohol consumption not surprisingly showed a significant overall association with both time of day and day of week of injury (Wald tests significant at $P<0.05$ for day of week and $P<0.001$ for time of day; model adjusted for gender and age). Injuries occurring on Saturdays and Sundays showed associations with acute consumption. In addition, night-time injuries were shown to be associated with acute consumption $(\mathrm{OR}=3.08$; 95\% CI: 1.75-5.43; reference period, 16:00-23:59), but day-time injuries were shown to be associated with absence of acute consumption $(\mathrm{OR}=0.27 ; 95 \%$ CI: 0.15-0.48). 


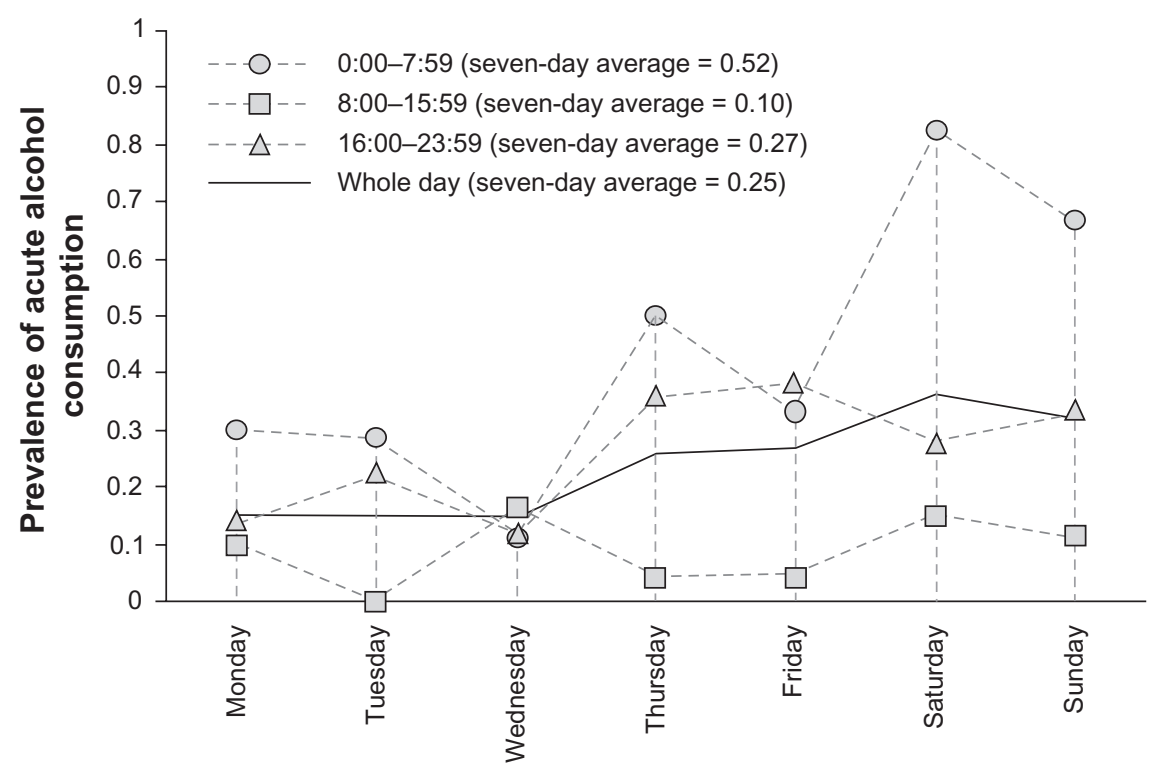

Figure I Prevalence of acute alcohol consumption among ED patients according to time of injury.

Adjusted for participant's gender and age, an overall association with HED was observed for day of week (Wald tests significant at $P<0.05$ ), but not for time of day. Injuries occurring on Saturdays showed increased odds for HED compared with those occurring on Mondays $(\mathrm{OR}=2.69$; 95\% CI: 1.26-5.76). By contrast, neither day of week nor time of day was associated with risky volume of alcohol consumption.

Finally, no effect of interaction terms (between time and day) was significant when estimated in the final set of regression models (at a $5 \%$ level of significance; results not presented).

\section{Discussion}

Half of all night-time injuries and as much as 8 in 10 of those taking place during the night between Friday and Saturday occurred after alcohol consumption. The distribution of these alcohol-related injuries was strongly associated with the time of occurrence, as in previous studies. ${ }^{10-12}$ However, our results argue for the absence of synergetic (ie, interaction) effect between time of day and day of week in the etiology of alcohol-related injuries; a finding reported, to our knowledge, for the first time in the literature. Confirming the implicit knowledge of medical staff with this regard, these results

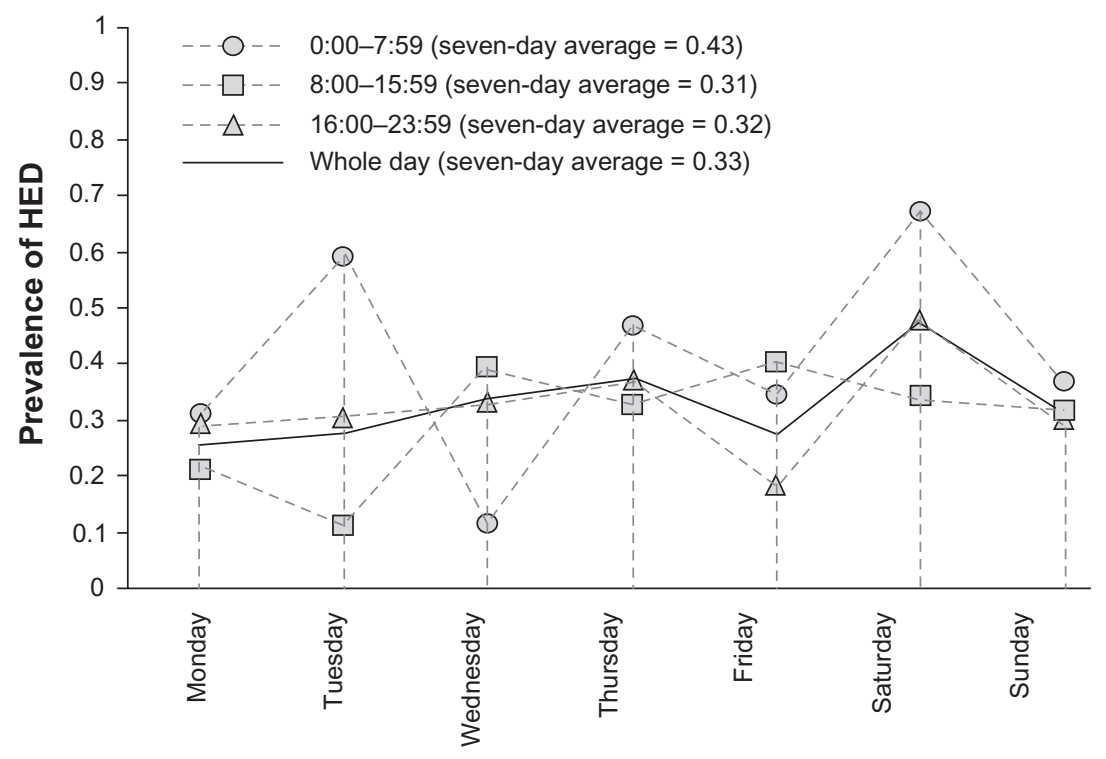

Figure 2 Prevalence of HED among ED patients according to time of injury. 


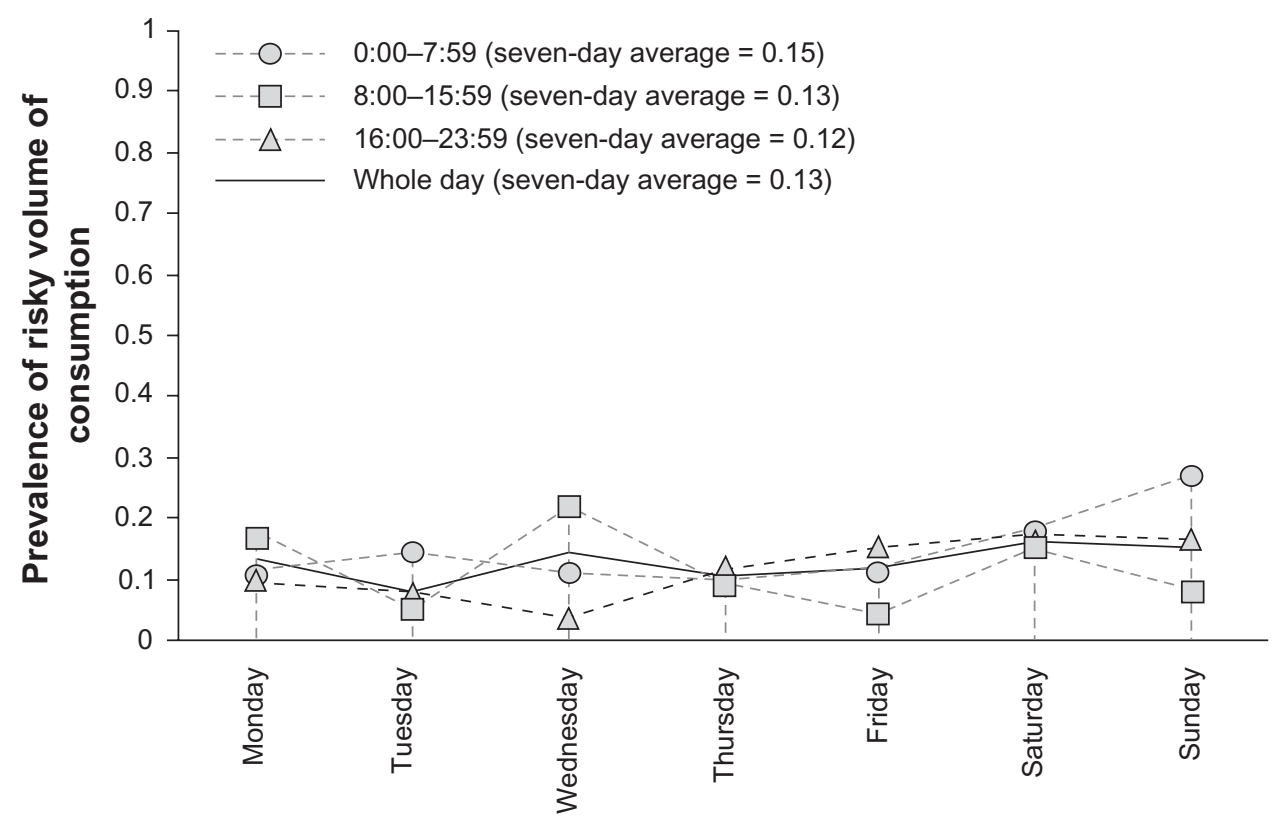

Figure 3 Prevalence of risky volume of alcohol consumption among ED patients according to time of injury.

highlight the importance of considering the time dimension of an injury when providing emergency care, eg, to prevent possible harmful consequences of the combination of alcohol and medical drugs or anesthetic agents. ${ }^{18,19}$

As described in previous studies, heavy episodic drinkers show a propensity for trajectories of drinking concentrated to weekends, which influences their risk for alcohol-related adverse consequences, and injuries, during this period. ${ }^{4}$ Our findings point in the same direction as HED was associated with day of injury (prevalence and ORs peaking on Saturday) but not time of day (this lack of statistical association could, however, be due to low number of cases in the sample). Though, the categorical combination of time and day, in addition to the main effects of each variable, was not associated with HED in the final regression model, noteworthy variations in prevalence of HED were recorded across the week. For instance, the difference in night-time prevalence between Tuesday and Wednesday is surprising $(57.1 \%$ vs 11.1\%). However, with less than 10 injuries, these specific periods had the smallest case numbers of all time/day combinations. Interpreting crude differences between these periods imply, thus, to keep in mind the important sensitivity of crude prevalence in case of small subsamples.

Self-reported data may challenge the reliability of our results. Yet, a study shows corroboration between self-reported and biological measures of acute alcohol consumption in a subsample

Table I Results of the regression models of acute alcohol consumption (acute), HED, and risky volume of alcohol consumption (volume) on day of week and time of day

\begin{tabular}{|c|c|c|c|c|c|c|}
\hline & \multicolumn{2}{|l|}{ Acute } & \multicolumn{2}{|l|}{ HED } & \multicolumn{2}{|l|}{ Volume } \\
\hline & Wald (df), sig & $\mathrm{OR}^{\mathrm{b}}(95 \% \mathrm{Cl})$ & Wald (df), sig & $\mathrm{OR}^{\mathrm{b}}(95 \% \mathrm{CI})$ & Wald (df), sig & $\mathrm{OR}^{\mathrm{b}}(95 \% \mathrm{CI})$ \\
\hline Day $^{a}$ & I3.4 (6), $P<0.05$ & & $12.9(6), P<0.05$ & & $2.9(6), \mathrm{ns}$ & \\
\hline Tuesday & & $0.97(0.33-2.89)$ & & $0.97(0.40-2.45)$ & & $0.55(0.15-1.96)$ \\
\hline Wednesday & & $0.96(0.35-2.67)$ & & $1.93(0.85-4.38)$ & & I.II (0.4I-2.97) \\
\hline Thursday & & $\mathrm{I} .64(0.6 \mathrm{I}-4.37)$ & & $1.91(0.81-4.49)$ & & $0.73(0.23-2.26)$ \\
\hline Friday & & I.88 (0.73-4.82) & & $1.24(0.53-2.89)$ & & $0.83(0.29-2.83)$ \\
\hline Saturday & & $2.85(1.19-6.82)$ & & $2.69(1.26-5.76)$ & & $1.22(0.48-3.07)$ \\
\hline Sunday & & $2.59(1.01-6.66)$ & & I.II (0.48-2.58) & & $1.18(0.43-3.23)$ \\
\hline Time $^{\mathrm{a}}$ & $47.1(2), P<0.001$ & & $2.3(2), \mathrm{ns}$ & & $0.5(2), \mathrm{ns}$ & \\
\hline 0:00-7:59 & & $3.08(1.75-5.43)$ & & $1.56(0.88-2.77)$ & & $1.28(0.62-2.68)$ \\
\hline $8: 00-15: 59$ & & $0.27(0.15-0.48)$ & & $1.17(0.73-1.88)$ & & $1.02(0.55-1.87)$ \\
\hline
\end{tabular}

Notes: ${ }^{2}$ Reference categories: Monday/ 16:00-23:59; ' $\mathrm{O}$ Rs (Odds ratios) adjusted for gender and age.

Abbreviations: HED, heavy episodic drinking; $\mathrm{Cl}$, confidence interval. 
of our participants. ${ }^{20}$ Also, the items and criteria used to measure hazardous alcohol consumption are similar to the ones used in the Alcohol Use Disorders Identification Test ${ }^{21}$ and their validity is regarded as high in epidemiological studies. ${ }^{22-24}$

Further, the exclusion of severely injured patients, unable to answer interview questions, implies that our results cannot easily be extrapolated to that group. The sampling frame nevertheless secured the time representativity needed for the study purposes.

ED admissions provide an opportunity for targeted interventions aimed at influencing the alcohol consumption of injured people and thereby lowering the alcohol-related burden of injury and disease..$^{2,25,26}$ Injuries sustained under the influence of alcohol (ie, acute consumption) and injuries sustained by people with hazardous alcohol consumption, ie, respectively with "at health risk" volumes of consumption or with frequent episodes of heavy consumption, concern specific populations, and accordingly distinct target groups for interventions. Accordingly, the fact that acute alcohol consumption is significantly associated with both time of day and day of week, HED with day of week, and risky volume of consumption with none may not only have implications for the triage and care of injured patients in the ED. For instance, these findings have also potential implication for interventions aimed at influencing the alcohol consumption patterns of injury patients presenting to the ED. This is particularly the case as undifferentiated screening and interventions are not likely to affect all patients equally.

\section{Conclusions}

In conclusion, acute alcohol consumption and HED show a specific time distribution for injuries, but risky volumes of consumption does not. It remains nonetheless unclear whether these results, observed for all kind of ED-treated injuries aggregated, would remain steady if specific injury mechanisms, and intentional injuries in particular, were to be considered. These findings nevertheless suggest that time of injury can be a key indicator of potential alcohol involvement; an important feature in clinical perspectives since presence of alcohol in the organism is known to be a crucial element in the diagnosis and treatment of injured patients.

\section{Acknowledgments}

The Swiss National Science Foundation supported the original study (grant 3200B0-105967) as well as the participation of Hervé Kuendig on the present article (grant PBSKB-119860/1).

\section{Disclosure}

The authors report no conflicts of interest in this work.

\section{References}

1. Cherpitel CJ. Alcohol and injuries: a review of international emergency room studies since 1995. Drug Alcohol Rev. 2007;26(2): 201-214.

2. National Institute on Alcohol and Alcoholism (NIAAA). Alcohol Alert - Brief Intervention. No. 66. Washington, DC: US Department of Health and Human Services, NIAAA; 2005.

3. Arfken CL. Temporal pattern of alcohol consumption in the United States. Alcohol Clin Exp Res. 1988;12(1):137-142.

4. Heeb JL, Gmel G, Rehm J, Mohler-Kuo M. Exploring daily variations of drinking in the Swiss general population. A growth curve analysis. Int J Methods Psychiatr Res. 2008;17(1):1-11.

5. Gmel G, Heeb JL, Rezny L, Rehm J, Mohler-Kuo M. Drinking patterns and traffic casualties in Switzerland - matching survey data and police records to design preventive action. Public Health. 2005;119(5):426-436.

6. Mäkelä $P$, Martikainen $P$, Nihtilä E. Temporal variation in deaths related to alcohol intoxication and drinking. Int $J$ Epidemiol. 2005;34(4):765-771.

7. Smith SM, Goodman RA, Thacker SB, Burton AH, Parsons JE, Hudson P. Alcohol and fatal injuries: temporal patterns. Am J Prev Med. 1989;5(5):296-302.

8. Cherpitel CJ, Parés A, Rodés J. Prediction of alcohol-related casualties in the emergency room: a US-Spain comparison. J Stud Alcohol. 1993;54(3):308-314.

9. Soderstrom CA, Kufera JA, Dischinger PC, Kerns TJ, Murphy JG, Lowenfels A. Predictive model to identify trauma patients with blood alcohol concentrations $>$ or $=50 \mathrm{mg} / \mathrm{dl}$. J Trauma. 1997;42(1): 67-73.

10. Wells S, Graham K. Aggression involving alcohol: relationship to drinking patterns and social context. Addiction. 2003;98(1):33-42.

11. Soffer D, Zmora O, Klausner JB, et al. Alcohol use among trauma victims admitted to a level I trauma center in Israel. Isr Med Assoc J. 2006;8(2):98-102.

12. Puljula J, Savola O, Tuomivaara V, Pribula J, Hillbom M. Weekday distribution of head traumas in patients admitted to the emergency department of a city hospital: effects of age, gender and drinking pattern. Alcohol Alcohol. 2007;42(2):474-479.

13. Gmel G, Kuendig H, Rehm J, Schreyer N, Daeppen JB. Alcohol and cannabis use as risk factors for injury - a case-crossover analysis in a Swiss hospital emergency department. BMC Public Health. 2009;9:40.

14. Kuendig H, Hasselberg M, Gmel G, Daeppen JB, Laflamme L. Acute and usual drinking among emergency trauma patients: a study on alcohol consumption and injury patterns. Injury prevention. 2009;15(4):270-274.

15. WHO Collaborative Study Group on Alcohol and Injuries. WHO Collaborative Study on Alcohol and Injury: Final Report. Geneva: Department of Mental Health and Substance Abuse and Department of Injuries and Violence Prevention, World Health Organization; 2007.

16. US Department of Health and Human Services (USDHHS). The Physicians' Guide to Helping Patients With Alcohol Problems. Rockville, MD: US Department of Health and Human Services, Public Health Service, National Institute of Health (NIH), National Institute on Alcohol Abuse and Alcoholism (NIAAA); 1995.

17. SPSS INC. SPSS Base 15.0 user's guide, Chicago, IL, SPSS Inc; 2006.

18. Baxter K ed. Stockley's Drug Interactions. 7th ed. London: Pharmaceutical Press; 2006.

19. Meyers HB, Zepeda SG, Murdock MA. Alcohol and trauma. An endemic syndrome. West J Med. 1990;153(2):149-153.

20. Gmel G, Kuendig H, Augsburger M, Schreyer N, Daeppen JB. Do objective measures of blood alcohol concentrations make more sense than self-reports in emergency department studies? J Addict Med. 2008;2(2):96-102. 
21. Babor TF, Higgings-Biddle JC, Saunders JB, Monteiro GM. Audit - The Alcohol Use Disorders Identification Test: guidelines for use in primary care. In: World Health Organization (WHO), DOHASD, ed. Screening and Brief Intervention: For Alcohol Problems in Primary Care. 2nd ed. Geneva, WHO; 2001.

22. Saunders JB, Aasland OG, Babor TF, De La Fuente JR, Grant M. Development of the Alcohol Use Disorders Identification Test (AUDIT): WHO Collaborative Project on Early Detection of Persons with Harmful Alcohol Consumption - II. Addiction. 1993;88(6):791-804.

23. Feuekes GIJ, Vant Veer P, Van Staveren WA, Kok FJ. Alcohol intake assessment: the sober facts. Am J Epidemiol. 1999;150(1):105-112.
24. Gmel G, Rehm J. Measuring alcohol consumption. Contemp Drug Probl. 2004;31(3):467-540

25. Gentilello LM. Alcohol interventions in trauma centers: the opportunity and the challenge. J Trauma. 2005;59 (Suppl 3):S18-S20.

26. Nilsen P, Baird J, Mello MJ, et al. A systematic review of emergency care brief alcohol interventions for injury patients. J Subst Abuse Treat. 2008;35(2):184-201.

\section{Publish your work in this journal}

Open Access Emergency Medicine is an international, peer-reviewed, open access journal publishing original research, reports, editorials, reviews and commentaries on all aspects of emergency medicine. The manuscript management system is completely online and includes a very quick and fair peer-review system, which is all easy to use.
Visit http://www.dovepress.com/testimonials.php to read real quotes from published authors. 